\title{
Facile and Sustainable Modification for Improving the Adsorption Ability of Sugarcane Bagasse Towards Cationic Organic Pollutants
}

\section{Pengcheng Luan}

South China University of Technology https://orcid.org/0000-0001-8896-3263

Jianming Liao

South China University of Technology

\section{Li Chen}

South China University of Technology

\section{Yishan Kuang}

South China University of Technology

\section{Xi Zhang}

South China University of Technology

\section{Yuxiang Zhang}

South China University of Technology

\section{Yikui Zhu}

South China University of Technology

\section{Yonghong Dai}

Guangxi Boguan Environmental Products Co., Ltd.

\section{Lihuan Mo}

South China University of Technology

Jun Li ( $\nabla$ ppjunli@scut.edu.cn )

South China University of Technology https://orcid.org/0000-0001-8242-6184

\section{Research Article}

Keywords: sugarcane bagasse, ozone modification, cationic organic pollution, biosorption

Posted Date: November 16th, 2021

DOI: https://doi.org/10.21203/rs.3.rs-1029529/v1

License: (c) (1) This work is licensed under a Creative Commons Attribution 4.0 International License.

Read Full License 
Version of Record: A version of this preprint was published at Biomass Conversion and Biorefinery on March 24th, 2022. See the published version at https://doi.org/10.1007/s13399-022-02551-9. 
1 Facile and sustainable modification for improving the adsorption

2 ability of sugarcane bagasse towards cationic organic pollutants

3 Pengcheng Luan\#, Jianming Liao\#, Li Chen, Yishan Kuang, Xi Zhang, Yuxiang Zhang, Yikui

4 Zhu, Yonghong Dai, Lihuan Mo, Jun $\mathrm{Li}^{*}$

5 Abstract: Using low-cost agro-industrial wastes and by-products derived from

6 lignocellulosic biomass for adsorption is believed to an affordable and sustainable way to tackle

7 the burning issue of cationic pollution in the marine, while its relatively low adsorption

8 capability limits its large-scale application. Chemical modifications to improve the adsorption

9 abilities of lignocellulosic biomass usually has problems such as long reaction time, high operational cost, rigorous reaction conditions (high temperature and pressure) as well as the second pollution. In this study, a green, rapid, simple, and mild method was developed by using ozone to improve the adsorption abilities of sugarcane bagasse (SB). The effects of ozone

Jun Li* - State Key Laboratory of Pulp and Paper Engineering, South China University of Technology, Guangzhou, 510641, China; Email: ppjunli@scut.edu.cn

Pengcheng Luan\# - State Key Laboratory of Pulp and Paper Engineering, South China University of Technology, Guangzhou, 510641, China

Jianming Liao" - State Key Laboratory of Pulp and Paper Engineering, South China University of Technology, Guangzhou, 510641, China

Li Chen - State Key Laboratory of Pulp and Paper Engineering, South China University of Technology, Guangzhou, 510641, China

Yuxiang Zhang - State Key Laboratory of Pulp and Paper Engineering, South China University of Technology, Guangzhou, 510641, China

Yikui Zhu - State Key Laboratory of Pulp and Paper Engineering, South China University of Technology, Guangzhou, 510641, China

Yonghong Dai - Guangxi Boguan Environmental Products Co., Ltd., Guangxi, 547000, China Lihuan Mo - State Key Laboratory of Pulp and Paper Engineering, South China University of Technology, Guangzhou, 510641, China

\# P. L. and J.L. contributed equally to this work. 
modification on the SB and its related adsorption abilities towards cationic polymers were quantitatively investigated. Results showed that ozone modification under very low ozone consumption $(\sim 1.5 \mathrm{wt} \%)$ could efficiently increase the carboxyl groups, change the chemical compositions of SB, and does not significantly change its morphology, thereby ensuring the good recovery and adsorption performance of SB. The maximum adsorption rate and capacity of SB for positively charged methylene blue (MB) were increased about $33.3 \%$ and $11.3 \%$ than the original SB. Besides, ozone modified SB maintained its high adsorption capability even at high $\mathrm{NaCl}$ concentration $(0.6 \mathrm{M})$. For cationic polymer with high charge densities, the adsorption capacity of milled SB increased about $125.4 \%$.

Key words: sugarcane bagasse, ozone modification, cationic organic pollution, biosorption

\section{Introduction}

Ocean, accounting for $71 \%$ of the total area of the earth, is of crucial importance not only to the worldwide energy systems but also to the nutrient supplies. Statistics show that more than 155 million tons of seafood are taken from the ocean every year, providing at least $20 \%$ of total animal proteins for 3.1 billion people. ${ }^{1}$ Besides, they are also important sources of amino acids, micronutrients, vitamins, and the only natural dietary source of $n-3$ polyunsaturated fatty acids, which are essential for the normal growth of young children. ${ }^{2}$ However, with the fast development of world industry in recent decades and occasionally occurred marine pollution emergencies, marine pollution has seriously damaged the marine ecological environment and thus adversely affected the food safety of seafood. Major marine pollutants include chemicals and plastics. Among them, cationic organic pollutants, such as 
cationic dyes (MB, methyl orange, etc.), are one of the main chemical pollutants, which have strong carcinogenic and mutagenic effects and can enter into the human consumers' bodies by the bioaccumulation, causing long-term toxic effects. ${ }^{3}$ Moreover, in the marine environment, cationic organic pollutants have the features of long duration, wide spreading, and difficult to control. Therefore, effective removal of cationic organic pollutants in the ocean is urgent and necessary.

Currently, the main strategies for the removal of cationic organic pollutants in the water bodies include physical (adsorption, membrane separation, etc.), chemical (oxidation, coagulation, etc.), and biological methods (aerobic and anaerobic treatment) or a combination of two or three above methods. ${ }^{4}$ However, since most cationic organic pollutants have high resistance due to their complex chemical structure and the particularity of the marine environment (high salinity and vast area), most of the above methods are costly, poorly feasible, and have secondary pollution concerns.

Recently, adsorption by using low-cost lignocellulosic biomass, especially for the agroindustrial wastes and by-products, to remove the cationic organic pollutants from the marine environment is considered a promising technology because of its simple operation process and high feasibility. ${ }^{5}$ Among those agro-industrial wastes and by-products, sugarcane bagasse (SB), in the form of pulpy fibrous material, is the main by-product of sugar industry after crushing the sugarcane to extract their juice. Because sugarcane from Nature is the world's largest crop by production quantity with an annual output of more than 1.8 billion tons, SB is a widely available, cost effective, sustainable, and carbon neutral material. SB is commonly used as the primary fuel source for sugar mills and sometimes for pulping. The use of low-cost SB to 
adsorb cationic pollutants can realize the reuse of resources and is sustainable and affordable.

Moreover, the SB after adsorption can be regenerated for continued use or burned to provide energy. Nevertheless, for large-scale applications, the main limitation of SB is their relatively low adsorption capacity due to their very limited anionic groups. ${ }^{5}$ Furthermore, the complexity of SB, mainly composed of cellulose (45-55 wt \%), hemicellulose (20-25wt\%), and lignin (18$24 \mathrm{wt} \%$ ) (Figure 1) ${ }^{6}$ makes it difficult to be efficient chemical modified towards all three components. Various agents have been used to cationic modify the lignocellulosic biomass, including acids (citric acid, succinic anhydride, acrylonitrile, and 2-mercaptobutanedioic acid), bases (sodium hydroxide and sodium carbonate), oxidants (periodate, sodium hypochlorite, and potassium permanganate), and many other chemical compounds (thionyl chloride, epichlorohydrin, acrylonitrile, and hydroxylamine). ${ }^{7,8}$ However, most of those modification reactions need long reaction time, high operational cost, and rigorous reaction conditions (high temperature and pressure). Additionally, extra efforts need to be paid to the second pollution caused by the modification reactions. Therefore, finding green modification ways to improve the adsorption performance of lignocellulosic biomass has a practical significance.

Ozone represents a promising modification reagent for increasing the anionic groups of materials because it's reactive, green, and cheap. Ozone is a strong oxidant with an extremely high oxidation potential of $2.07 \mathrm{eV}$. It has been used to react with oxidizable organics and even inorganic substances under normal temperature and pressure into products with carbonyl or carboxyl groups. For lignocellulosic biomass, previous studies showed that ozone could oxidize all three main components of lignocellulosic biomass (cellulose, hemicellulose, and lignin) into carboxyl-containing structures, indicating the feasibility of using ozone 
modification to increase its adsorption performance. Additionally, both the raw material and reaction product of ozone are usually oxygen, indicating the green nature of ozone modification.

In this study, we developed a simple and green method by using ozone to increase the adsorption performance of sugarcane bagasse (SB) under normal temperature and pressure (Figure 1). The effects of ozone on the chemical compositions, total and surface anionic groups (carboxyl groups), and the absorption behavior of SB were investigated. Two types of cationic polymers were chosen in this study to verify the adsorption abilities of the ozone modified SB towards cationic pollutants with different charge densities, including poly dimethyl diallyl ammonium chloride (PDADMAC) with a high charge density and MB with a low charge density. Ozone modified SB showed enhanced adsorption capability towards cationic organic pollutants in the aqueous environment with low ozone consumption and high yield. Considering ozone as an efficient and green reactant, ozone modified lignocellulosic biomass could be a promising adsorbent for removal of the cationic organic pollutants in the marine.

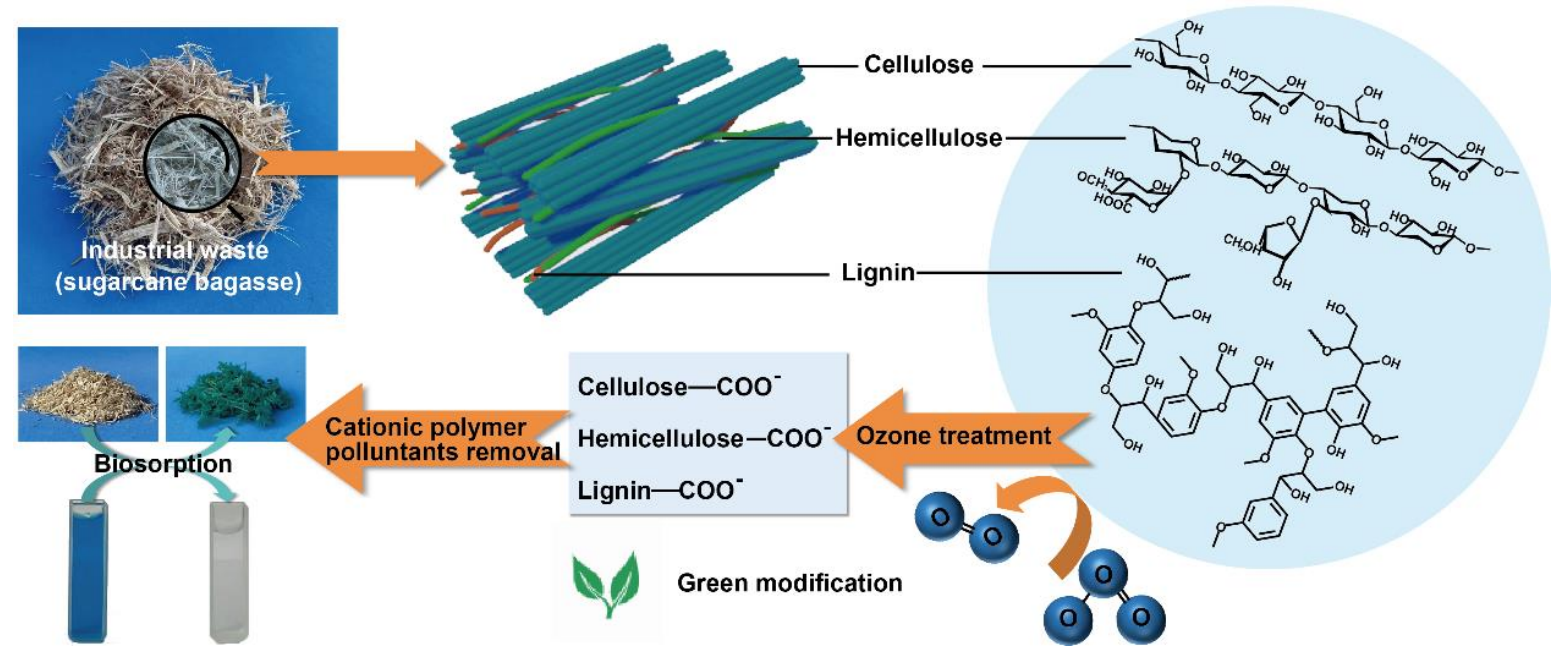

Figure 1. Ozone modification of industrial waste (sugarcane bagasse) to increase its anionic groups for cationic organic pollutants. 
94

95

96

97

\section{Materials and methods}

Materials. SB grown in South China was provided by a local pulp mill (Guangxi). It was washed three times with distilled water and dried at $60^{\circ} \mathrm{C}$ before use. The dried SB was ground and crushed into small pieces by using a cutting mill (CM 200, Beijing Grinder Instrument Co., Ltd., China) equipped with a 4-mesh discharge screen. The crushed SB powder was vibrating separated by a circular vibrating screen (8411, Shangyu fifty-four Instrument Factory, China). The 20-40 mesh fraction of SB was collected and used in this experiment. Analytical grade $\mathrm{H}_{2} \mathrm{SO}_{4}, \mathrm{NaOH}, \mathrm{NaCl}$, and $\mathrm{MB}$ were used in this study.

Ozone treatment. $10 \mathrm{~g}$ of SB was firstly treated by $10 \mathrm{wt} \% \mathrm{H}_{2} \mathrm{SO}_{4}$ at $\mathrm{pH} 2.0$ for $30 \mathrm{~min}$. Then the mixture was diluted by $\mathrm{H}_{2} \mathrm{SO}_{4}$ solution $(\mathrm{pH}=2.0)$ to $40 \mathrm{wt} \%$ consistency. The obtained SB was transferred to a gas washing bottle. Ozone was fed from the bottom of stacked bagasse for $2.5 \mathrm{~min}, 5.0 \mathrm{~min}, 7.5 \mathrm{~min}$, and $10.0 \mathrm{~min}$, respectively. Ozone generator (GM 3, Primozone, Sweden) was used to generate ozone. The ozone concentration was detected by an ozone concentration detector (UV-2100, Usideal, China). The whole process was conducted under normal temperature $\left(23-25^{\circ} \mathrm{C}\right)$ and pressure. Ozone consumption under different treatment time was listed in Table 4.

Table 4. Ozone consumption at different treatment time.

\begin{tabular}{ccccc}
\hline Sample & $\begin{array}{c}\text { Ozone concentration } \\
\left(\mathrm{g} / \mathrm{m}^{3}\right)\end{array}$ & $\begin{array}{c}\text { Flow rate } \\
(\mathrm{L} / \mathrm{min})\end{array}$ & $\begin{array}{c}\text { Time } \\
(\mathrm{min})\end{array}$ & $\begin{array}{c}\text { Ozone } \\
\text { consumption }(\%)\end{array}$ \\
\hline 0 & 0.0 & 0.0 & 0.0 & 0.0 \\
1 & 154.7 & 1.5 & 2.5 & 1.5 \\
2 & 156.5 & 1.5 & 5.0 & 3.0 \\
3 & 152.2 & 1.5 & 7.5 & 4.4 \\
4 & 166.8 & 1.5 & 10.0 & 7.7 \\
\hline
\end{tabular}


113 Compact, Zeiss, Germany) was used to investigate the morphology of SB at the ozone dosage 114 of $0,1.5 \mathrm{wt} \%$, and $7.7 \mathrm{wt} \%$. a Nicolet 520P spectrometer with a resolution of $4 \mathrm{~cm}^{-1}$ and 64 scans per sample.

Composition analysis of SB. The contents of cellulose, hemicellulose, and lignin in SB were examined according to NREL/TP-510-42623 issued by National Renewable Energy hydrolysate was then filtered by $\mathrm{G}_{4}$ filter with constant weight. The hydrolyzed monosaccharides were performed using High Performance Liquid Chromatography (HPLC, Agilent 1260, Agilent Technologies, USA). The acid-soluble lignin was performed using Visible UV Spectrophotometer (UV2600, Shimane Shimadzu Corporation, Japan). The G4 filter was washed by distilled water until the filtrate was neutral and transferred into oven at the weight of its ash is the weight of acid-insoluble lignin. hemicellulose) is calculated as follows:

$$
\text { Selectivity }_{\mathrm{n}-(\mathrm{n}+1)}=\frac{\operatorname{Lignin}_{\mathrm{n}}-\operatorname{Lignin}_{\mathrm{n}+1}}{\operatorname{Carbohyd}_{\mathrm{n}}-\operatorname{Carbohyd}_{\mathrm{n}+1}}
$$


$133(\mathrm{n}+1)$; Lignin $\mathrm{n}$ and Carbohydr ${ }_{\mathrm{n}}$ represent the lignin content $(\mathrm{mg})$ and carbohydrates $(\mathrm{mg})$ of

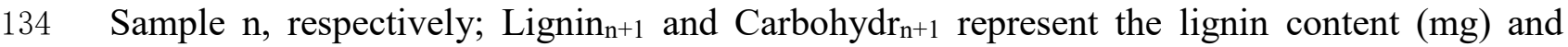
135 carbohydrates $(\mathrm{mg})$ of Sample $\mathrm{n}_{\mathrm{n}+1}$, respectively.

Determination of the total carboxyl and carbonyl groups in SB. Before the determination,

137

the ozone-treated SB was milled into powder by the planetary ball mill (PQ-N2, Across International, USA). The total carboxyl content in SB was determined by conductometric titration. About $0.3 \mathrm{~g}$ of milled $\mathrm{SB}$ and $5 \mathrm{~mL}$ of $0.01 \mathrm{~mol} / \mathrm{L} \mathrm{NaCl}$ solution were dispersed into $50 \mathrm{~mL}$ of deionized water. The $\mathrm{pH}$ of the suspension was controlled at the range of 2.5-3.0 by $0.1 \mathrm{~mol} / \mathrm{L} \mathrm{HCl}$ solution. Before titration, the suspension was purged with an $\mathrm{N}_{2}$ atmosphere at $25^{\circ} \mathrm{C}$ for $30 \mathrm{~min}$. The suspension was titrated by $0.1 \mathrm{~mL}$ standardized $0.1 \mathrm{~mol} / \mathrm{L} \mathrm{NaOH}$ with 60 $\mathrm{s}$ intervals until the $\mathrm{pH}$ value reached 11 , the electrical conductivity and the volume of $\mathrm{NaOH}$ were recorded for the calculation of the total carboxyl content. ${ }^{33}$

The copper number was determined according to Tappi standard method (T $430 \mathrm{~cm}-09$ ). The carbonyl content was linear correlated with the copper number and calculated by the following equation: ${ }^{34}$

$$
\mathrm{CCOA}=\frac{(\mathrm{Cu} \#-0.07)}{0.06}
$$

Where CCOA represents the total carbonyl content of SB (mmol/kg) and Cu\# represents the copper number $(\%)$.

XPS analysis. Before XPS analysis, ozone-treated SB was extracted by dichloromethane to remove the extractives according to standard Tappi T $204 \mathrm{~cm}-07$. XPS analysis was performed 
by X-ray Photoelectron Spectroscopy (Axis Ultra DLD, Kratos Analytical, UK) using a monochromated $\mathrm{Al} \mathrm{K} \alpha$ source $(5 \mathrm{~mA}, 15 \mathrm{kV})$. For the high-resolution spectra, the analytical area was $0.7 \mathrm{~mm} \times 0.3 \mathrm{~mm}$ with a pass energy of $40 \mathrm{eV}$. All samples were tested three times. All spectra were fitted by XPS peak 4.1 using Lorentzian-Gaussian line shape (20\% Lorentzian contribution) after Tougaard background correction.

The surface lignin $\left(\varnothing_{\text {Lignin }}\right)$ of SB was calculated by the O/C ratios based on the XPS spectrum (Eq. 3) ${ }^{35}$. The calculated equation is as follows:

$$
\emptyset_{\text {Lignin }}=\frac{O / C_{(\text {sample })}-O / C_{(\text {lignin-free } S B)}}{O / C_{(\text {lignin })}-O / C_{(\text {lignin-free } S B)}}
$$

Where $\mathrm{O} / \mathrm{C}$ (sample) is the $\mathrm{O} / \mathrm{C}$ ratio of the $\mathrm{SB}$ sample after extraction, $\mathrm{O} / \mathrm{C}$ (lignin) is the $\mathrm{O} / \mathrm{C}$ value of lignin $(0.33) .{ }^{36}$ The theoretical $\mathrm{O} / \mathrm{C}$ value of cellulose is 0.83 , the $\mathrm{O} / \mathrm{C}$ value of the hemicellulose of SB is approximately $0.8,{ }^{37,38}$ and the $\mathrm{O} / \mathrm{C}$ value of delignified pulp is $0.8 .^{39}$

Herein, the $\mathrm{O} / \mathrm{C}$ (lignin-free $\mathrm{SB}$ ) value of 0.8 was used in the equation to represent the lignin-free of SB.

Determination of MB adsorption. $200 \mathrm{~mL}$ of $100 \mathrm{mg} / \mathrm{L} \mathrm{MB}$ solution was shaken with $1 \mathrm{~g}$ of SB using an air-bath shaker $(200 \mathrm{rpm})$ at $30^{\circ} \mathrm{C}$. The $\mathrm{pH}$ of the initial solution was 6.0 adjusted by $0.1 \mathrm{~N} \mathrm{HCl}$ solution and $0.1 \mathrm{~N} \mathrm{NaOH}$ solution. The concentration of residual $\mathrm{MB}$ was examined at different time intervals using a UV-VIS spectrophotometer (UV-2600, Shimadzu, Japan) at the wavelength of $665 \mathrm{~nm}$. A standard calibration curve was built by different concentrations of $\mathrm{MB}$ solution $(0,1,2,3,4,5 \mathrm{mg} / \mathrm{L})$ with a linear correlation coefficient of 0.999. The adsorbed MB was calculated as the following equation: 


$$
\mathrm{Q}=\frac{\left(C_{0}-C\right) V}{M}
$$

173

Where Q represents the content of adsorbed MB $(\mathrm{mg} / \mathrm{g})$; V represents the volume of the solution (L); $\mathrm{C}_{0}$ represents the initial concentration of $\mathrm{MB}(\mathrm{mg} / \mathrm{L})$; $\mathrm{C}$ represents the concentration of $\mathrm{MB}(\mathrm{mg} / \mathrm{L})$, and $\mathrm{M}$ represents the mass of the sample $(\mathrm{mg})$. The equilibrium concentration of the residual MB was examined after 24 hours of adsorption.

Determination of adsorption of PDADMAC. The adsorption capability of SB towards PDADMAC was determined using a particle charge detector (PCD-03 pH, Mütek ${ }^{\mathrm{TM}}$, Germany). $0.1 \mathrm{~g}$ milled sample was dispersed in $10 \mathrm{~mL}$ deionized water and titrated by $0.001 \mathrm{~N}$ standardized PDADMAC solution. The adsorption capability was calculated as the following equation:

$$
\mathrm{q}=\frac{c * V}{m}
$$

Where q represents the adsorption capability of SB towards PDADMAC (mmol/kg); V represents the volume of PDADMAC used $(\mathrm{ml})$; $\mathrm{c}$ represents the concentration of PDADMAC $(\mathrm{mmol} / \mathrm{ml})$, and $\mathrm{m}$ represents the weight mass of the sample $(\mathrm{kg})$.

\section{Results and discussion}

Ozone modification of SB. Ozone modification we developed was green and sustainable without requiring harsh reaction conditions (high temperature and pressure), toxic chemicals, and high chemical load. Besides, the original shape and size of SB were also maintained, thereby ensuring that the modified SB could be easily recycled. The detailed ozone modification process of SB was illustrated in Figure 2a. Under normal temperature and 
pressure, a continuous flow of ozone with a concentration of $150 \sim 170 \mathrm{~g} / \mathrm{m}^{3}$ produced by the ozone generator entered the gas-washing bottle containing $10 \mathrm{~g} \mathrm{SB}$ at the flow rate of $\sim 1.5$ $\mathrm{L} / \mathrm{min}$. The total ozone consumption was between $1.5 \sim 7.7 \%$ of the weight of SB. After the ozone treatment, there was no significant change in the morphology of SB at the macro scale, but the color became lighter (Figure $2 b_{1} \sim 2 b_{3}$ ), which could be due to the decrease of the lignin content and the chromogenic groups in SB. Lignin is rich in the chromophore groups and therefore is the main color source of most lignocellulosic biomass. Ozone could effectively cleave the chromophore groups of lignin and further oxidize them to carboxyl or aldehyde groups, resulting in a decrease in the polymerization degree (DP) and an increase in the solubility of the lignin, which ultimately lead to the decreased lignin content and chromophore groups in $\mathrm{SB} .^{9}$

To investigate the effects of ozone on the microstructure of SB, the SB before and after ozone modification were characterized by SEM. As can be seen from Figure $2 \mathrm{c}_{1}, 1 \mathrm{c}_{3}$, and $1 \mathrm{c}_{5}$, similar to the macrostructure, the microstructure of SB was also basically maintained. While the chemical compositions of the SB surface had undergone major changes (Figure $2 \mathrm{c}_{2}, 1 \mathrm{c}_{4}$, and $1 \mathrm{c}_{6}$ ), which played an important role in the adsorption rate. As shown in Figure $2 \mathrm{c}_{2}$, the surface of the original SB was covered by melted substances, which could be composed of lignin. ${ }^{10}$ When the ozone consumption was $1.5 \mathrm{wt} \%$, the surface of ozone-modified SB (Figure 2c4) had significantly fewer melted substances, but the melted substances could be clearly observed again when the ozone consumption attained $7.7 \mathrm{wt} \%$ (Figure $2 \mathrm{c}_{6}$ ). This revealed that the partially dissolved lignin modified by ozone could re-deposit onto the surface of SB due to the increase in $\mathrm{pH}$ during the washing process. ${ }^{10}$ 


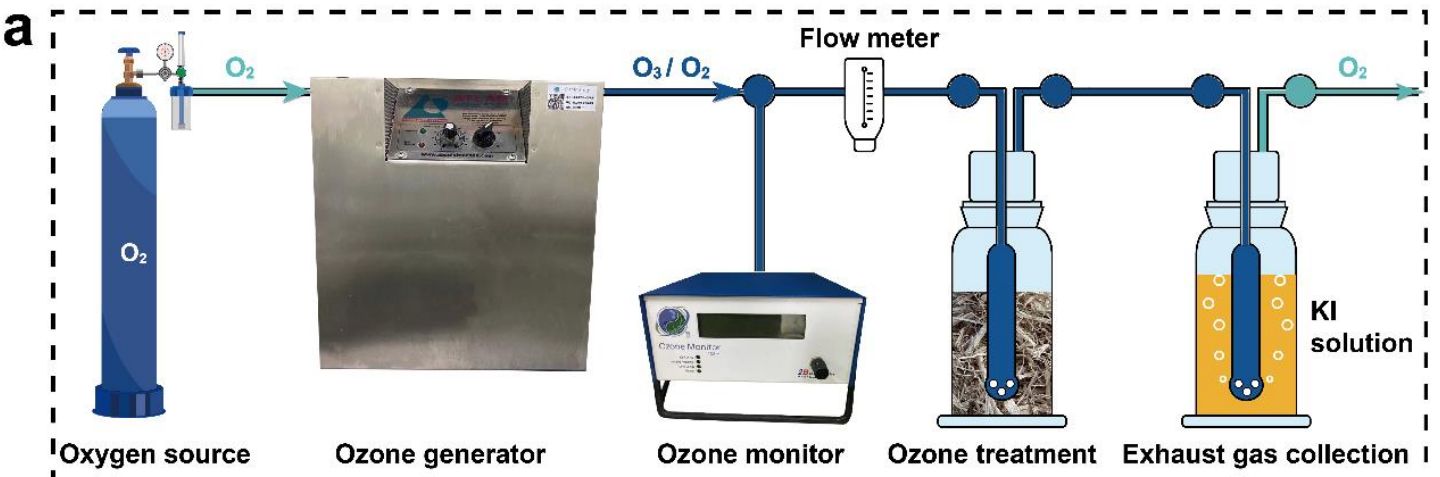

I - - - - - - - - - - - - - - - - - - - - - - - - - - - - - - - - -

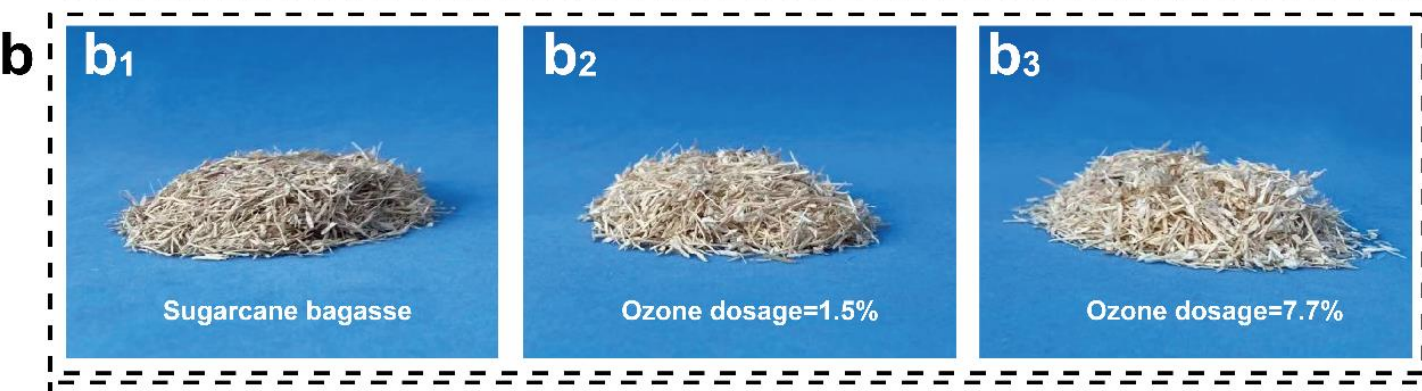

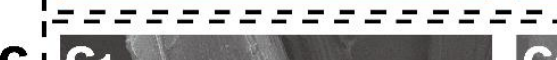
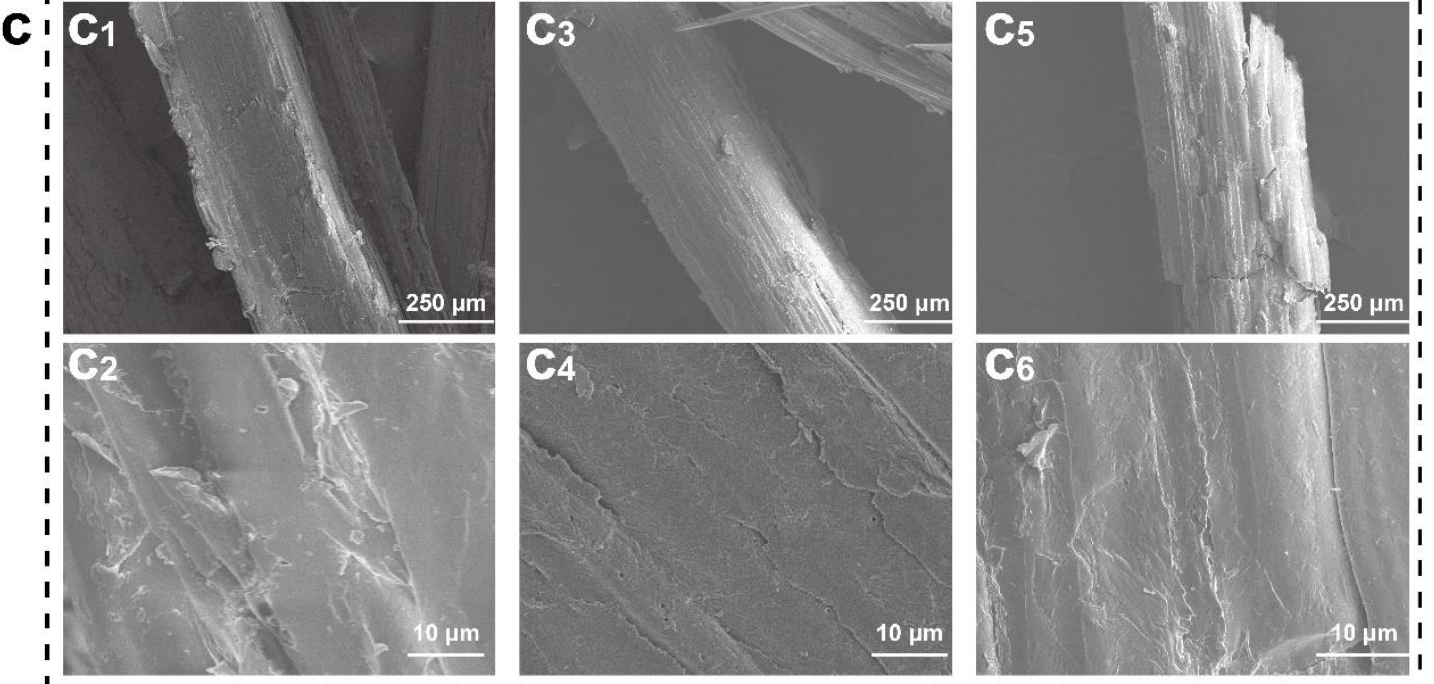

Figure 2 (a) Schematic image of ozone modification process. (b) Photos showing original

216 SB $\left(b_{1}\right)$ and ozone-modified SB with an ozone consumption of $1.5 \mathrm{wt} \%\left(\mathrm{~b}_{2}\right)$ and $7.7 \mathrm{wt} \%\left(\mathrm{~b}_{3}\right)$.

(c) SEM images of original SB ( $c_{1}$ and $\mathrm{c}_{2}$ ) and ozone-modified SB with an ozone consumption

218 of $1.5 \mathrm{wt} \%\left(\mathrm{c}_{3}\right.$ and $\left.\mathrm{c}_{4}\right)$ and $7.7 \mathrm{wt} \%\left(\mathrm{c}_{5}\right.$ and $\left.\mathrm{c}_{6}\right)$.

Effects of ozone on the compositions and functional groups of SB. To improve the

to increase its carboxyl content. Figure $3 \mathrm{a}_{1}-\mathrm{a}_{3}$ showed the ozone modification towards the three 
main components (cellulose, hemicellulose, and lignin) in SB. For lignin, ozone has high reactivity and selectivity to its aromatic and olefinic structures. Ozone first reacts with the double bonds in lignin through 1,3-dipolar addition to form primary ozonide, which is then hydrolyzed into muconic acid derivatives (containing carbonyl and carboxyl groups) and hydrogen peroxide (Figure 3a 1 ). ${ }^{9}$ Moreover, with the further increase in ozone consumption, the aromatic structures and double bonds of the side chains of lignin would be cleaved to small molecules of high hydrophilic fatty acids, causing partial removal of lignin from the SB. ${ }^{9}$ For carbohydrates (cellulose and hemicellulose), ozone can directly attack the glycosidic bonds to form hydrogen trioxide, which was then cleaved to form lactone and oxygen. Finally, carbohydrates were hydrolyzed to form a carboxyl-containing structure (Figure $3 \mathrm{a}_{2}$ and $\left.3 \mathrm{a}_{3}\right){ }^{9}$

To further investigate the effects of ozone modification towards the compositions and functional groups of SB, Fourier Transform Infrared Spectroscopy (FTIR) was used (Figure 3b). Regarding the change of functional groups, after ozone modification, the adsorption bands at $1637 \mathrm{~cm}^{-1}$ and $1735 \mathrm{~cm}^{-1}$ assigned to the $\mathrm{C}=\mathrm{O}$ stretching of carboxylate $\left(-\mathrm{COO}^{-}\right)$and free carboxyl groups $(-\mathrm{COOH})$ were strengthened, which confirmed the effects of ozone on increasing the carboxyl groups of SB. Regarding the change of compositions, it can be seen that the absorbance peaks at $1425 \mathrm{~cm}^{-1}, 1514 \mathrm{~cm}^{-1}$, and $1604 \mathrm{~cm}^{-1}$ assigned to the ring breathing vibrations of benzene in lignin structure were weakened after ozone modification. Meanwhile, the absorbance peak at $897 \mathrm{~cm}^{-1}$ assigned to the $\mathrm{C}-\mathrm{O}-\mathrm{C}$ stretching vibration of glycosidic bond of carbohydrates (cellulose and hemicellulose) was strengthened. This indicated that ozone exhibited high selectivity to aromatic structures of lignin than the glycosidic bonds of carbohydrates. Besides, due to the decrease content of the lignin, the SB exhibited more 
244 hydroxyl groups (3406 $\mathrm{cm}^{-1} \mathrm{OH}$ stretching vibration strengthened) after ozone modification.

245 Overall, ozone can react with all the three main components in SB to generate carboxyl-

246 containing derivatives, indicating the high feasibility of using ozone to improve the adsorption

247 capability of SB towards cationic organic pollutants. 


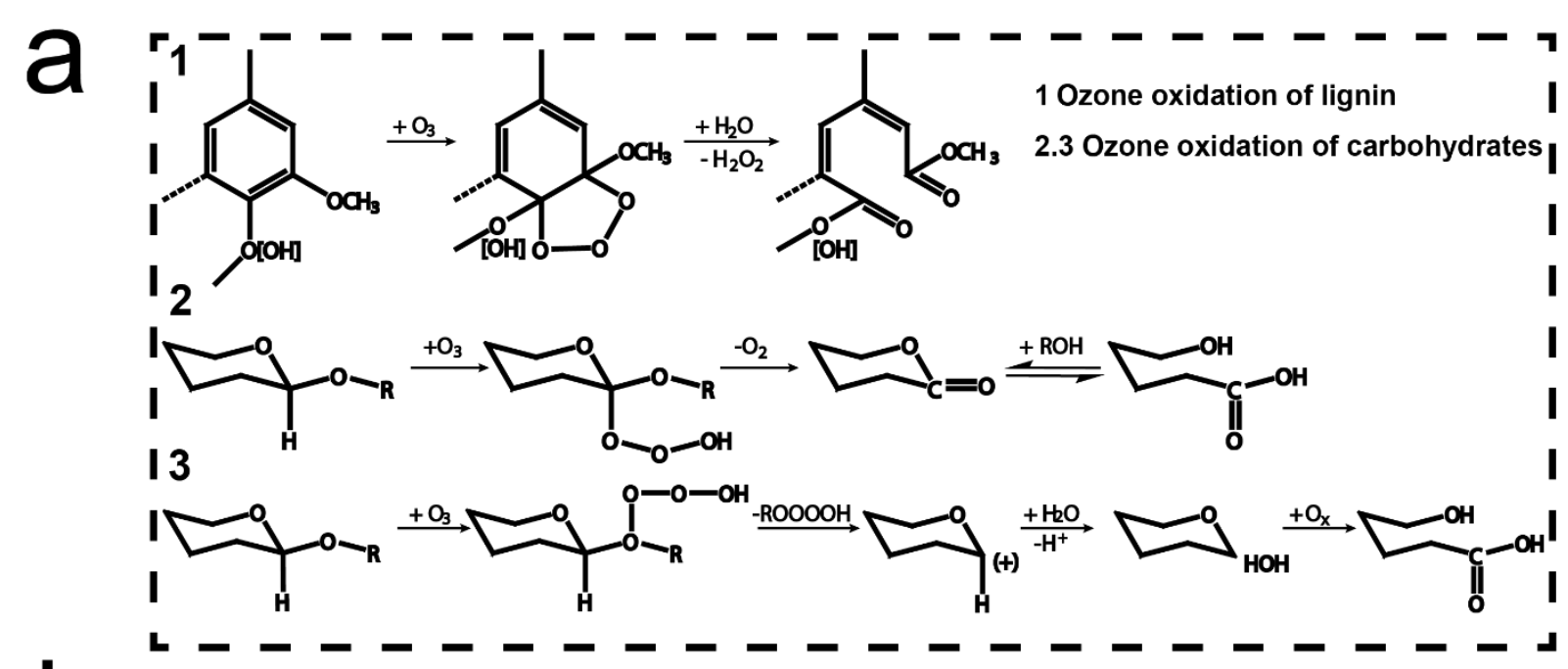

b

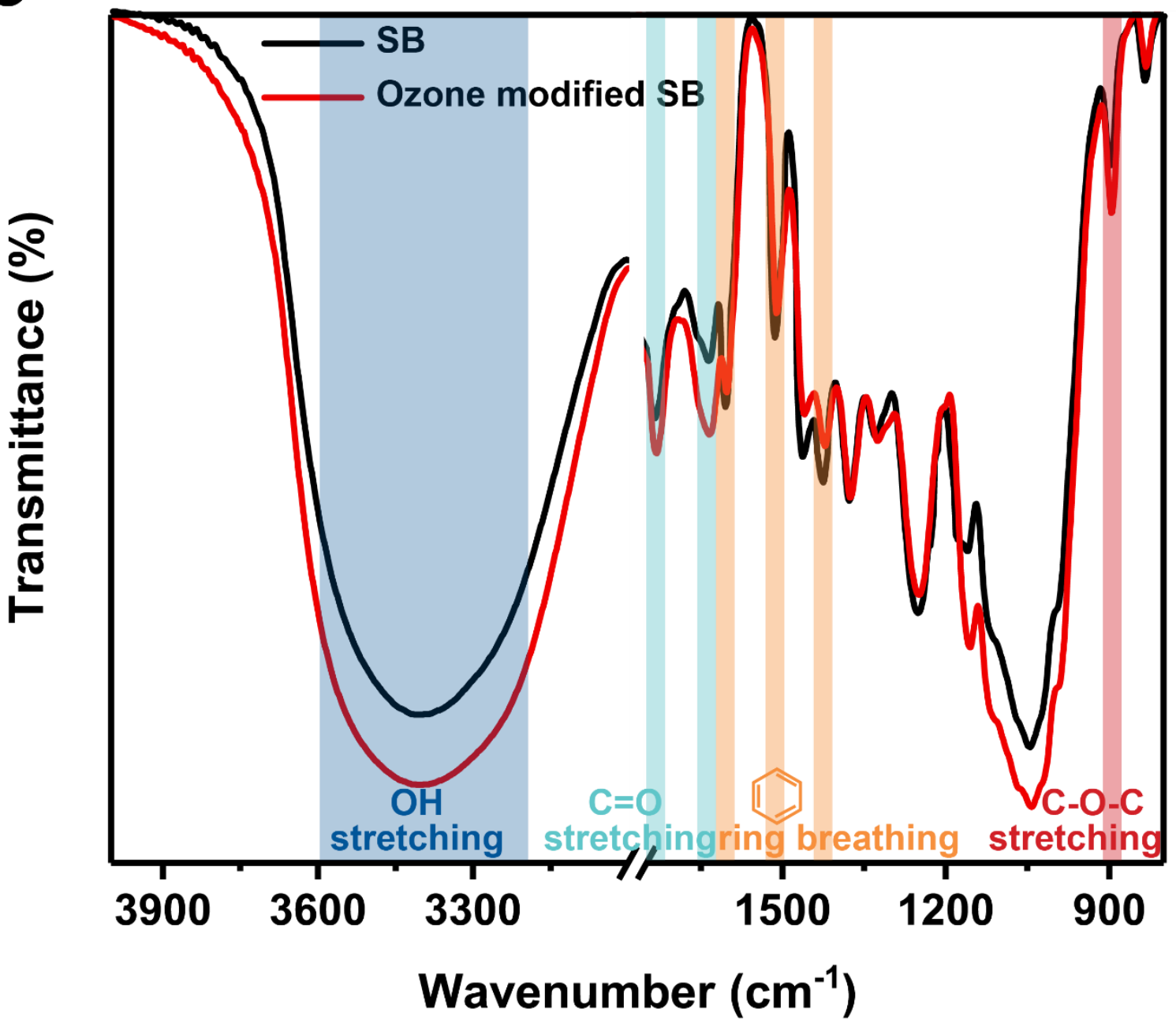

249 Figure 3 (a) Ozone modification reaction towards the three main components (cellulose, 250 hemicellulose, and lignin) of SB. (b) FTIR spectrum of SB before (black line) and after ozone 
modification (1\#, red line). could directly show the effects of ozone modification on the cellulose, hemicellulose, and consumption were illustrated in Figure 4a. Since ozone is an effective reactant, the contents of all three components decreased with the increase of ozone consumption. When the ozone to $7.7 \mathrm{wt} \%$ (Sample 4), a high yield (88.4\%) was still obtained, the decrease of total lignin for cellulose and $6.1 \%$ for hemicellulose).

Ozone showed high selectivity to lignin, especially when the lignin content of SB was high (Figure 4b). That was because ozone has higher reactivity towards aromatic and side-chainolefin of the lignin structure ${ }^{9}$ than the glycosidic bonds of carbohydrates. The selectivity of ozone towards lignin decreased quickly as the decrease of total lignin content. Meanwhile, the selectivity of ozone towards cellulose and hemicellulose increased quickly (Figure 4b). This indicated that the oxidation tended to occur on the surface of SB rather than inside the SB due to its compact structure, despite the presence of lots of pores. Once the lignin on the surface was reduced to some extent, the oxidation of the cellulose and hemicellulose exposed from the covered lignin would increase, thus causing the rapid weight loss of carbohydrates (cellulose and hemicellulose). In addition, according to Ben, et al., the hydroxyl contents of cellulose, 
hemicellulose, and lignin were about $18.52 \mathrm{mmol} / \mathrm{g}, 14.43 \mathrm{mmol} / \mathrm{g}$, and $5.29 \mathrm{mmol} / \mathrm{g}$, respectively. ${ }^{11}$ The high weight loss of lignin and low weight loss of cellulose and hemicellulose indicated that the relative content of the hydroxyl group in ozone-treated SB increased, which was beneficial to increase the hydrophilic properties of SB and therefore improve the adsorption rate of SB.

Interestingly, compared to the original SB, only acid-insoluble lignin in total lignin decreased, while acid-soluble lignin increased during the ozone modification. The increased acid-soluble lignin value remained constant after the ozone consumption reached $1.5 \mathrm{wt} \%$ (sample 1). This could be attributed to the decrease of DP of acid-insoluble lignin and the increase of carboxyl groups, which transformed acid-insoluble lignin into acid-soluble lignin. ${ }^{10}$ Acid-soluble lignin would be further oxidized to small molecule acids or even to carbon dioxide and water. ${ }^{9}$ The constant value of acid-soluble lignin could be due to the balance between the oxidation of acid-insoluble lignin and acid-insoluble lignin. Additionally, the increase of acid-soluble lignin also meant the increase of carboxyl groups of lignin in SB.

It can be concluded from above that ozone showed high selectivity towards lignin and increase the functional groups of SB with low ozone consumption. The increase of functional groups in SB, including hydroxyl and carboxyl groups, could be benefited for its adsorption abilities in terms of adsorption capability and adsorption rate. To further find out the effects of ozone on the functional groups of ozone-treated SB, the total and surface functional groups (carboxyl and carbonyl groups) were tested.

Characterization of functional groups in the ozone modified SB. The contents of 
carbonyl and carboxyl groups are important parameters reflecting the reaction behavior of ozone to SB and the potential of ozone modification for anionic groups increase. The change of total carbonyl and carboxyl groups with the ozone consumption was illustrated in Figure 4c and 4d. After ozone modification, both the contents of carboxyl and carbonyl groups increased. The carboxyl groups increased first and then tended to gentle as the increase of ozone consumption. Meanwhile, the carbonyl groups increased first and then slightly decreased with the increase of ozone consumption. This change could be closely related to the composition change during the ozone modification. Before ozone consumption attained at $3.01 \mathrm{wt} \%$ (Sample 1 and Sample 2), the increase of carboxyl and carbonyl groups was accompanied by the rapid decrease of lignin content (Figure 4a). A certain amount of carbonyl and carboxyl groups were formed through the reaction of ozone with the olefin and aromatic structures of lignin. $^{12}$

When ozone consumption was beyond $3.01 \mathrm{wt} \%$ (Sample 3 and Sample 4), the composition change was dominated by the degradation of carbohydrates, thus causing the corresponding changes of functional groups (Figure 4a). This process can be divided into three steps $^{13}$ : the formation of carbonyl groups, followed by oxidation to carboxyl groups, and decarboxylation. ${ }^{14}$ The reason for the steady-state of carboxyl content could be that the rate of oxidation of the carbonyl groups to carboxyl groups was approximately equal to that of decarboxylation. ${ }^{14}$ Importantly, the total carboxyl and carbonyl groups were increased about $84.1 \%$ and $16.1 \%$ (Sample 1) with an ozone consumption of only $1.5 \mathrm{wt} \%$. Overall, ozone modification effectively increased the total content of carboxyl groups of SB under the conditions of high yield and low ozone consumption. 

significant effects on its physicochemical properties and are the important factors for the adsorption rate from dilute aqueous solutions. ${ }^{15-17}$ XPS analysis were used to determine the carboxyl and carbonyl contents on the surface of extractives-free SB (Figure 4e and 4f). The XPS analysis of extractives-free SB revealed four C peaks at 284.6, 286.3, 287.9, and 288.2 eV (Figure 4f), originating from $\mathrm{C} 1(\mathrm{C}-\mathrm{C}), \mathrm{C} 2(\mathrm{C}-\mathrm{O}), \mathrm{C} 3(\mathrm{O}-\mathrm{C}-\mathrm{O}$ and/or $\mathrm{C}=\mathrm{O})$, and $\mathrm{C} 4(\mathrm{O}-$ $\mathrm{C}=\mathrm{O}$ ), respectively. ${ }^{18}$ Carbohydrates exhibited two peaks in the XPS spectrum, C2 (alcohols and ethers), and C3 (ketones and aldehydes). The peak C1 (aliphatic carbon) only originated from the lignin of extractives-free $\mathrm{SB}$, because the extractives have been removed by extraction and $\mathrm{C}-\mathrm{C}$ bonds do not exist in the carbohydrates (cellulose and hemicellulose). increased with the increase of the ozone consumption. According to the results of composition analysis, there were two stages in the ozone modification process, namely rapid weight loss of lignin and rapid weight loss of carbohydrates. Similar stages could also exist for the surface composition of SB. Since $\varnothing_{\text {Lignin }}$ is the relative content of lignin, the decrease of $\varnothing_{\text {Lignin }}$ could be mainly due to the partial dissolution of the lignin during the first stage. The increase of $\varnothing_{\text {Lignin }}$ could be due to the abovementioned degradation of carbohydrates during the second stage and the increased content of re-deposited lignin. According to the results of component analysis, the content of dissolved lignin in the system increased with the ozone consumption, resulting in an increase in the content of re-deposited lignin, which was consistent with the 
SEM results.

The change of carboxyl groups on the surface of SB can be indicated by the relative intensity of C4 (carboxylic acid and ester). In Table 1, both the content of carbonyl and carboxyl groups first increased and then decreased with the increase of ozone consumption. This result could be closely related to the carboxylation reaction of ozone and the surface composition change of SB. The carboxylation reaction of ozone towards all three components could significantly increase the carboxyl groups of SB and decrease the content of surface lignin. carboxyl content. The carboxyl groups on the SB surface increased dramatically during the ozone modification with a maximum increase of $257 \%$ at the ozone consumption of $3.0 \mathrm{wt} \%$. When the ozone consumption reached $7.7 \mathrm{wt} \%$, the carboxyl groups still increased about $132 \%$. Overall, after ozone treatment, the surface of SB contains increased anionic groups (carboxyl groups) and less hydrophobic lignin to expose the abundant hydroxyl groups, which could be beneficial to its adsorption rate. 

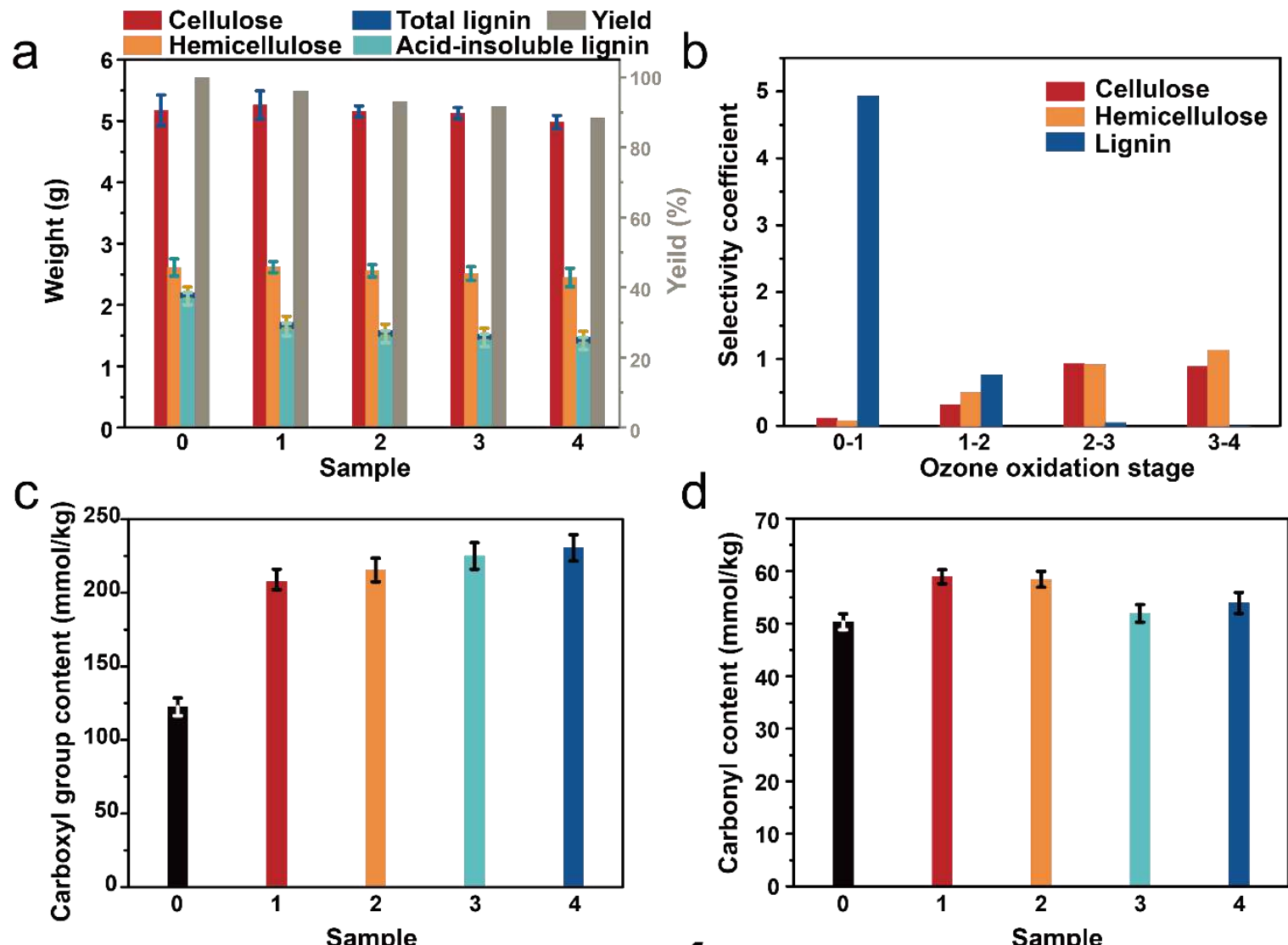

d

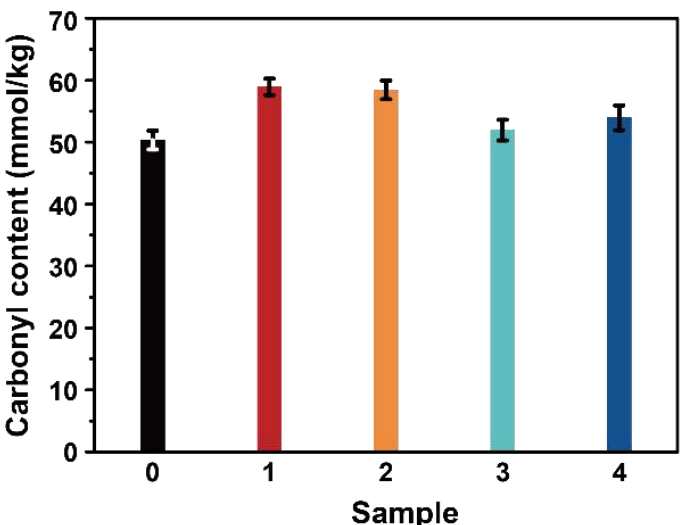

e
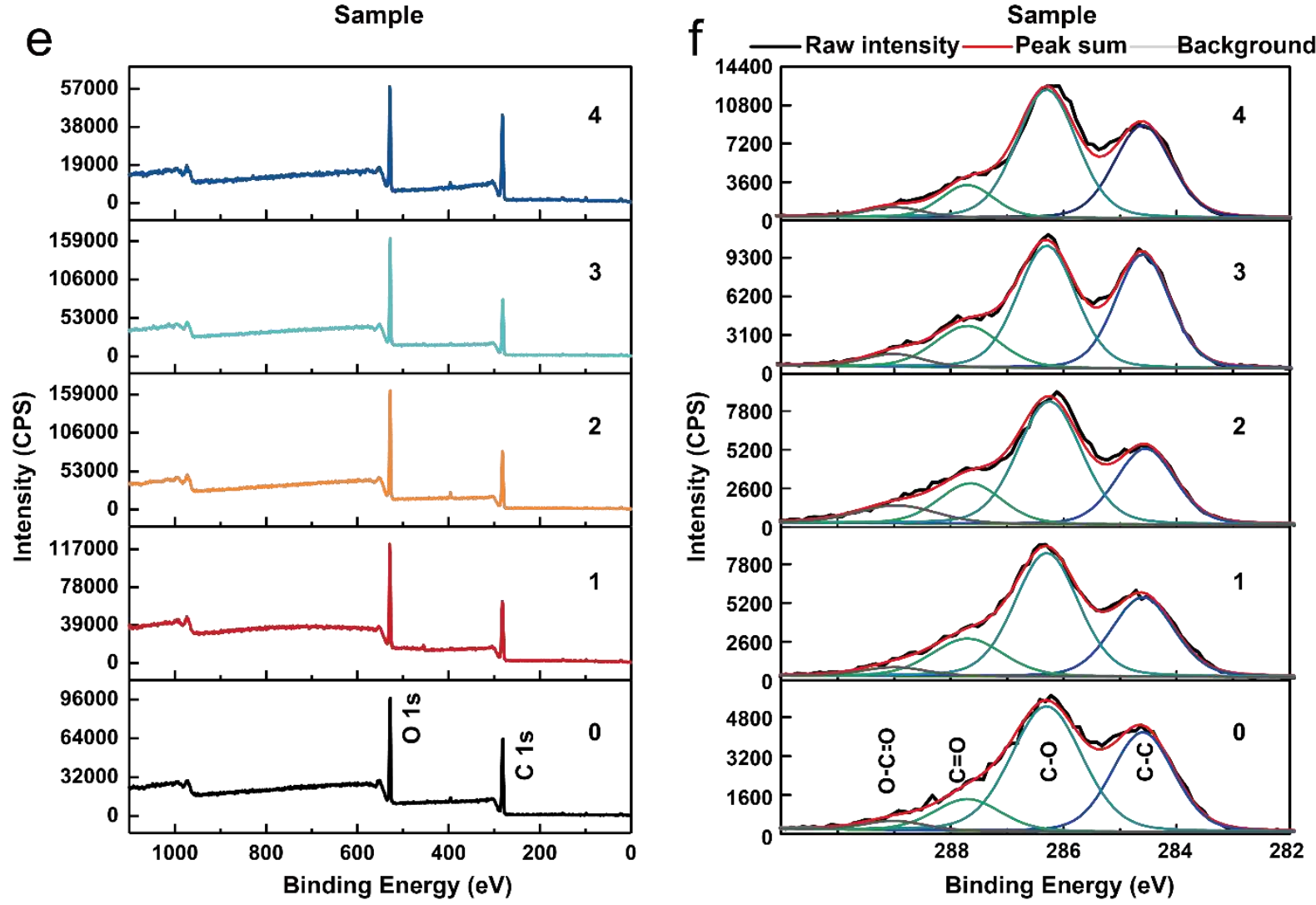

353 Figure 4 (a) Effects of different ozone consumption on the chemical compositions of ozone-

354 treated SB. (b) Selectivity coefficient change with ozone consumption. Effects of ozone 
consumption on the total carboxyl (c) and carbonyl groups (d) of the ozone-treated SB. The XPS spectra of extractives-free ozone-treated SB with different ozone consumption. (e) full survey, (f) C 1s high resolution XPS spectra.

Table 1 XPS analysis of the extractives-free ozone-treated SB with different ozone consumption.

\begin{tabular}{|c|c|c|c|c|c|c|c|}
\hline \multirow[t]{4}{*}{ Sample } & \multirow{4}{*}{$\begin{array}{c}\text { Ozone } \\
\text { consume } \\
\text { charge } \\
(\%)\end{array}$} & \multirow[t]{4}{*}{$\mathrm{O} / \mathrm{C}$} & \multicolumn{4}{|c|}{ Binding energy $(\mathrm{eV})$} & \multirow{4}{*}{$\begin{array}{c}\varnothing \text { Lignin } \\
(\%)\end{array}$} \\
\hline & & & $\mathrm{C} 1(\%)$ & C2 (\%) & C3 (\%) & C4 (\%) & \\
\hline & & & $\mathrm{C}-\mathrm{C}$ & $\mathrm{C}-\mathrm{O}$ & $\mathrm{C}=\mathrm{O}$ & $\mathrm{O}-\mathrm{C}=\mathrm{O}$ & \\
\hline & & & 284.6 & 286.3 & 287.9 & 288.2 & \\
\hline 0 & 0.0 & 0.50 & 35.6 & 49.6 & 12.0 & 2.8 & 65 \\
\hline 1 & 1.5 & 0.59 & 30.2 & 51.2 & 14.2 & 4.3 & 48 \\
\hline 2 & 3.0 & 0.60 & 26.4 & 48.8 & 14.8 & 10.0 & 47 \\
\hline 3 & 4.4 & 0.56 & 36.6 & 46.1 & 11.1 & 6.3 & 55 \\
\hline 4 & 7.7 & 0.52 & 34.4 & 47.1 & 12.1 & 6.5 & 61 \\
\hline
\end{tabular}

Adsorption of cationic organic pollutants by ozone-modified SB. To investigate the adsorption abilities of the ozone-modified SB towards cationic organic pollutants (Figure 5a), batch adsorption experiments were carried out by using $1 \mathrm{~g}$ of ozone-modified SB in $200 \mathrm{~mL}$ of $100 \mathrm{mg} \mathrm{L}^{-1} \mathrm{MB}$ solution with a $\mathrm{pH}$ of 6 at $30^{\circ} \mathrm{C}$. As illustrated in Figure $5 \mathrm{~b}$, the adsorption of MB can be divided into three stages, namely the rapid adsorption period, slow adsorption period, and the equilibrium adsorption period. ${ }^{19,20}$ The above three stages were controlled by film diffusion, intraparticle diffusion, and the physisorption and chemisorption, respectively. During the adsorption process, MB molecules first diffused from the solution to the external surface of the adsorbent (film diffusion), then migrated to the interior surface (intraparticle diffusion), and finally adsorbed on the surface sites of SB (physisorption or chemisorption). ${ }^{19}$,

${ }^{21}$ By increasing the hydrophilic groups (hydroxyl and carboxyl groups) and cation adsorption 
sites (carboxyl groups) of SB, the ozone-modified SB exhibited a higher adsorption rate, especially at the early stage of adsorption, as well as a higher adsorption capacity than that of the original SB (Figure 5b). Furthermore, according to the results of adsorption equilibrium experiments (listed in Table 3), among all the ozone-modified SB, Sample 1 exhibited the largest adsorption capability of $9.237 \mathrm{mg} / \mathrm{g} \mathrm{SB}, 11.3 \%$ higher than the original SB $(8.295 \mathrm{mg} / \mathrm{g}$ $\mathrm{SB}$ ), and largest adsorption rate of $0.624 \mathrm{mg} \cdot \mathrm{g}^{-1} \cdot \mathrm{min}^{-1}$ after 10 minutes of contact with $\mathrm{MB}$, $33.3 \%$ higher than original SB $\left(0.416 \mathrm{mg} \cdot \mathrm{g}^{-1} \cdot \mathrm{min}^{-1}\right)$. As the ozone consumption charge further increased, both the maximum adsorption rate and adsorption capacity of SB slightly decreased.

To reveal the mechanism of the ozone-modified SB participating in the MB adsorption process, three kinetic models were adopted, namely irreversible first-order, reversible firstorder, and pseudo-second-order models (Table 2). The irreversible first-order model is derived as the assumption that once adsorbed, the particle cannot diffuse along or desorb from the surface. From Figure 5c, the irreversible first-order model only fitted well at the first $20 \sim 30$ min of the adsorption process instead of the whole adsorption process, indicating the adsorption is dominated at the initial stage of adsorption rather than desorption. The reversible first-order model is derived under the assumption that the adsorption and desorption rate constants are equal to the equilibrium reaction rate constant. ${ }^{22,}{ }^{23}$ As for the pseudo-second-order model, which is contrary to the previous models, it assumes the "chemisorption" behaviour over the whole biosorption process. ${ }^{24}$

From Figure 5c $\sim$ and Table 3, compared to the other two models, pseudo-second-order model is the best fitted model for both original and ozone-modified SB with a $\mathrm{R}^{2}$ higher than 0.990. In addition, since the nonlinear regression method is believed to be more appropriate for 
determining the rate kinetic parameters, ${ }^{25,26}$ nonlinear pseudo-second-order kinetic model was also adopted in this study (Table 2). As shown in Figure 5f, the non-linear pseudo-second-order kinetic plots correlated well with the experimental data $\left(\mathrm{R}^{2}>0.990\right)$. The related adsorption parameters $\left(\mathrm{k}_{\mathrm{II}}\right.$ and $\mathrm{q}_{\mathrm{e}}$, Table 3$)$ were very close to that of linear pseudo-second-order model $\left(\mathrm{k}_{\mathrm{II}}\right.$ and $\left.\mathrm{q}_{\mathrm{e}}\right)$ and the experimental data $\left(\mathrm{q}_{\mathrm{e}}\right)$, which further confirmed that the pseudo-secondorder model could be suitable for investigating the adsorption mechanisms of SB towards MB.

This indicated that the adsorption of MB by SB was more like the chemisorption-based process involving ions exchange between cationic $\mathrm{MB}$ and functional groups (mainly $-\mathrm{OH}$ and $-\mathrm{COOH}$ ) of SB. ${ }^{27-29}$ Besides, instead of relying on the assumption that the rate-limiting step is the film diffusion, the rate-limiting step of the pseudo-second-order kinetic model assumed is chemisorption. ${ }^{28}$ Therefore, the change of maximum adsorption rate (MAR) and capacity could be closely related to the change of functional groups during the ozone modification.

The MAR changes of different ozone-modified SB with the increase of ozone consumption correlated well with the changes of hydroxyl and carboxyl groups on its surface, which can be indicated by $\mathrm{O} / \mathrm{C}$ ratios and $\mathrm{C} 4$ relative intensity in Table 1 . Since MAR was reached at the film diffusion stage, the increased hydrophilic hydroxyl and carboxyl groups on the surface could enhance the hydrophilicity, thereby promoting the permeation of water as well as the MB molecules through the film, and finally increasing the MAR.$^{30}$ Meanwhile, the change of adsorption rate also showed a similar trend. The increase of the carboxyl group content could lead to the increased chemisorption sites for cationic organic pollutants, which in turn increased the cationic adsorption capacity of ozone-modified SB. Therefore, the reason for the decrease of adsorption capability could be that the redeposited lignin as one of the 
important sources of adsorption sites (carboxyl groups) for MB could redissolve into the solution during the adsorption process, which therefore reduced its adsorption capability.

Table 2 Mathematical expressions of the three kinetic models.

\begin{tabular}{lll}
\hline Kinetic model & Equation & Integrated form \\
\hline Irreversible first-order & $\mathrm{dq} / \mathrm{dt}=\mathrm{k}_{\mathrm{I}}\left(\mathrm{Q}_{\mathrm{e}}-\mathrm{Q}\right)$ & $\log \left(\mathrm{Q}_{\mathrm{e}}-\mathrm{Q}\right)=\log \mathrm{q}_{\mathrm{e}}-\left(\mathrm{k}_{\mathrm{I}} / 2.303\right) \mathrm{t}$ \\
Reversible first-order & $\mathrm{dc} / \mathrm{dt}=\mathrm{k}_{1} \mathrm{C}-\mathrm{k}_{-1} \mathrm{X}$ & $-\ln \left(\left(\mathrm{C}-\mathrm{C}_{\mathrm{e}}\right) /\left(\mathrm{C}_{\mathrm{e}}-\mathrm{C}_{\mathrm{e}}\right)\right)=\mathrm{kt}$ \\
Pesudo-second-order & $\mathrm{dq} / \mathrm{dt}=\mathrm{k}_{\mathrm{II}}\left(\mathrm{Q}_{\mathrm{e}}-\mathrm{Q}\right)^{2}$ & $\mathrm{t} / \mathrm{Q}=1 /\left(\mathrm{k}_{\mathrm{II}} \mathrm{q}_{\mathrm{e}}{ }^{2}\right)+\mathrm{t} / \mathrm{q}_{\mathrm{e}}$ \\
Non-linear Pesudo- & $\mathrm{dq} / \mathrm{dt}=\mathrm{k}_{\mathrm{II}}\left(\mathrm{Q}_{\mathrm{e}}-\mathrm{Q}\right)^{2}$ & $\mathrm{Q}=\mathrm{k}_{\mathrm{II}} \mathrm{q}_{\mathrm{e}}{ }^{2} \mathrm{t} /\left(1+\mathrm{k}_{\mathrm{II}} \mathrm{q}_{\mathrm{e}}{ }^{2} \mathrm{t}\right)$ \\
second-order & & \\
\hline
\end{tabular}

Where $t$ is the adsorption time (min), $q$ is the amount of MB adsorbed per unit of SB at time $\mathrm{t}(\mathrm{mg} / \mathrm{g}), \mathrm{k}_{\mathrm{I}}$ is the rate constant for first-order kinetic model $\left(\mathrm{min}^{-1}\right)$, Q is amount of $\mathrm{MB}$ adsorbed per unit of SB at time $\mathrm{t}(\mathrm{mg} / \mathrm{g}), \mathrm{Q}_{\mathrm{e}}$ is the experimental amount of MB adsorbed per unit of SB $(\mathrm{mg} / \mathrm{g}), \mathrm{q}_{\mathrm{e}}$ is the calculated amount of dye molecules adsorbed per unit of $\mathrm{SB}(\mathrm{mg} / \mathrm{g})$, $\mathrm{k}_{1}$ is the forward reaction rate constant, $\mathrm{k}_{-1}$ is the reverse reaction rate constant, $\mathrm{k}$ is the equilibrium rate constant for e reversible kinetic model (equal to the ratio of $\mathrm{k}_{1}$ to $\mathrm{k}_{-1}$ ), $\mathrm{c}$ is the initial concentration of $\mathrm{MB}$ at time $\mathrm{t}(\mathrm{mg} / \mathrm{L}), \mathrm{X}$ is the $\mathrm{MB}$ in the solid phase, $\mathrm{C}_{0}$ is the initial concentration of $\mathrm{MB}(\mathrm{mg} / \mathrm{L}), \mathrm{Ce}$ is the equilibrium concentration of $\mathrm{MB}(\mathrm{mg} / \mathrm{L}), \mathrm{C}$ is the concentration of $\mathrm{MB}(\mathrm{mg} / \mathrm{L})$ at time $\mathrm{t}, \mathrm{k}_{\mathrm{II}}$ is the rate constant of pseudo-second-order kinetic $\operatorname{model}\left(\mathrm{g} \mathrm{mg}^{-1} \mathrm{~min}^{-1}\right)$.

Table 3 Kinetic rate constant related to the biosorption of MB onto ozone modified SB.

\begin{tabular}{llllll}
\hline & \multicolumn{5}{c}{ Sample } \\
\cline { 2 - 6 } & 0 & 1 & 2 & 3 & 4 \\
\hline \multicolumn{2}{l}{ Irreversible first-order } & & & \\
$\quad \mathrm{k}_{\mathrm{I}}$ & 0.033 & 0.042 & 0.033 & 0.029 & 0.030 \\
$\quad$ Calculated qe & 3.857 & 4.452 & 2.923 & 2.924 & 3.560 \\
$\mathrm{R}^{2}$ & 0.998 & 0.841 & 0.983 & 0.927 & 0.977 \\
Reversible first-order & & & & \\
$\quad \mathrm{K}$ & 0.045 & 0.033 & 0.027 & 0.030 & 0.041
\end{tabular}




\begin{tabular}{|c|c|c|c|c|c|}
\hline $\mathrm{R}^{2}$ & 0.827 & 0.983 & 0.942 & 0.977 & 0.775 \\
\hline \multicolumn{6}{|c|}{ Pesudo-second-order } \\
\hline $\mathrm{k}_{\mathrm{II}}$ & 0.016 & 0.027 & 0.026 & 0.019 & 0.019 \\
\hline Calculated $\mathrm{q}_{\mathrm{e}}$ & 7.886 & 8.540 & 8.295 & 8.117 & 8.143 \\
\hline $\mathrm{R}^{2}$ & 0.999 & 0.999 & 0.997 & 0.996 & 0.994 \\
\hline \multicolumn{6}{|c|}{ Non-linear Pesudo-second-order } \\
\hline $\mathrm{k}_{\mathrm{II}}$ & 0.016 & 0.027 & 0.026 & 0.019 & 0.019 \\
\hline Calculated $\mathrm{q}_{\mathrm{e}}$ & 7.886 & 8.540 & 8.295 & 8.117 & 8.143 \\
\hline $\mathrm{R}^{2}$ & 0.997 & 0.998 & 0.992 & 0.990 & 0.991 \\
\hline Experimental $\mathrm{q}_{\mathrm{e}}$ & 8.295 & 9.237 & 9.063 & 8.725 & 8.613 \\
\hline
\end{tabular}

430

Where $\mathrm{R}^{2}$ is the squared regression correlation coefficient.

When removing cationic pollutants from the ocean, it is important to consider the effect of $\mathrm{NaCl}$ concentration on the adsorption performance of adsorbent because the seawater contain a high concentration of salt ( $\sim 0.6 \mathrm{M} \mathrm{NaCl}$ solution). Figure $5 \mathrm{~g}$ showed the effect of the $\mathrm{NaCl}$ concentration on the adsorption capability of the SB and ozone modified SB (Sample 1) towards MB. Both the adsorption capability of SB and ozone modified SB decreased as the $\mathrm{NaCl}$ concentration increased, which could be due to the competitive effects between the $\mathrm{Na}^{+}$ and $\mathrm{MB}$ ions on the sites available for sorption. In addition, after ozone modification, the increased available sorption sites made the ozone modified SB more resistant to salt water than the original SB. The adsorption capability of original SB in $0.6 \mathrm{M} \mathrm{NaCl}$ solution decreased $29.0 \%$ than in $0.01 \mathrm{M} \mathrm{NaCl}$, while ozone modified SB only decreased $17.7 \%$.

To evaluate the adsorption performance of ozone-modified SB towards cationic polymers with high charges (for example, cationic polyelectrolytes), batch adsorption experiments were conducted by using $0.1 \mathrm{~g}$ milled ozone modified SB to adsorb the $0.001 \mathrm{~N}$ cationic PDADMAC. As shown in Figure 5h, the adsorption capability of ozone-modified SB first increased sharply, and then slightly decreased with the increase of the ozone consumption. The adsorption capacity of PDADMAC increased to $125.4 \%$ when the ozone consumption was only $1.5 \mathrm{wt} \%$ 
447 (Sample 1). This result was consistent with the change in MB adsorption capacity and the total 448 carboxyl groups. Negatively charged functional groups (carboxyl groups) played an important 449 role during the adsorption of PDADMAC. Since the pKa of carboxylic groups were about 5.4, 450 the carboxylic groups can dissociate into anionic groups at neutral $\mathrm{pH}$. The increase of 451 negatively charged carboxyl groups on the SB could increase the PDADMAC adsorption 452 because of the existence of chemical reactions or cation exchange between them. ${ }^{31,32}$ Therefore, 453 the increase of carboxyl groups by ozone modification can effectively increase the PDADMAC 454 adsorption of SB. 

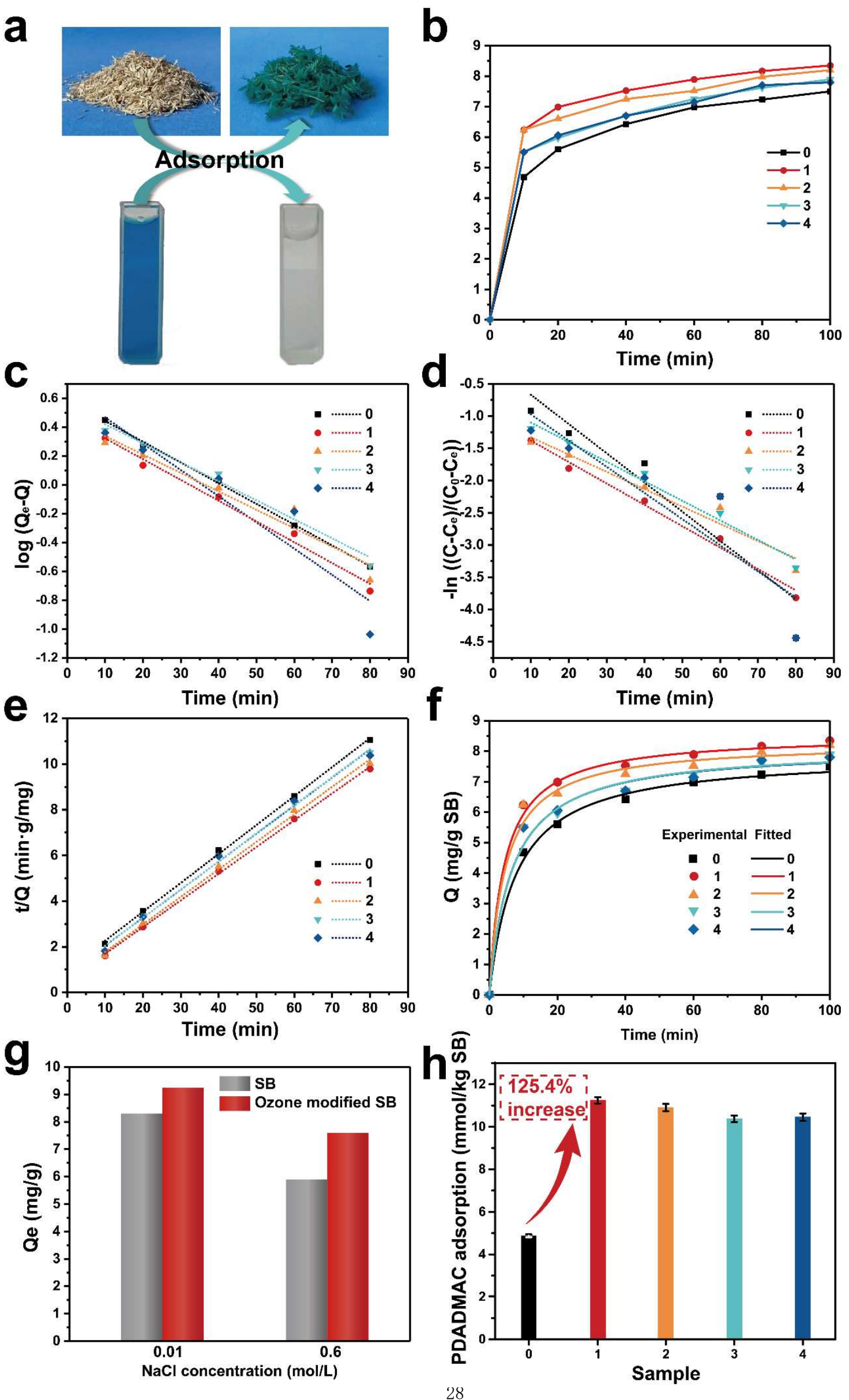
Figure 5 Adsorption of cationic organic pollutants by the ozone modified SB. (a) Schematic diagram of adsorption of cationic organic pollutants by the ozone modified SB, (b) the adsorption curves for MB onto the ozone modified $\mathrm{SB}$ ( $\mathrm{SB}$ concentration $=5 \mathrm{~g} / \mathrm{L}$, initial solution $\mathrm{pH}=6$, temperature $=30^{\circ} \mathrm{C}$ ), linear irreversible first-order $(\mathrm{c})$, reversible first-order $(\mathrm{d})$, pseudo-second-order (e), and non-linear pseudo-second-order (f) kinetic plots of MB adsorption onto different ozone modified $\mathrm{SB}$, $(\mathrm{g})$ effect of $\mathrm{NaCl}$ concentration $(0.01 \mathrm{M}$ and 0.6 M) on the adsorption capability of SB and ozone modified SB (Sample 1), (h) adsorption capacity of PDADMAC onto the different ozone modified SB.

Comparison with other adsorbents. Compared with the current commercial activated carbon, $\mathrm{SB}$, as the agro-industrial wastes and by-products has outstanding advantages in terms of carbon neutral, sustainability, cost efficiency, and recyclability (Figure 6). To improve the limited adsorption capability towards cationic pollutants and maintain its above advantages, this study uses ozone to make simple and green modification of SB. After ozone modification, the adsorption capacity of SB for cationic pollutants was efficiently improved with low ozone consumption, the morphology of bagasse was maintained to ensure its good recyclability, and the degraded lignin and carbohydrates could be biodegraded to ensure its sustainable performance. Furthermore, compared with other modification methods that require high chemical dosage, expensive chemical cost, and high process cost, the amount of ozone used for modification is $15 \mathrm{~kg} /$ ton sugarcane bagasse with a cost of only $\$ 72 /$ ton. 


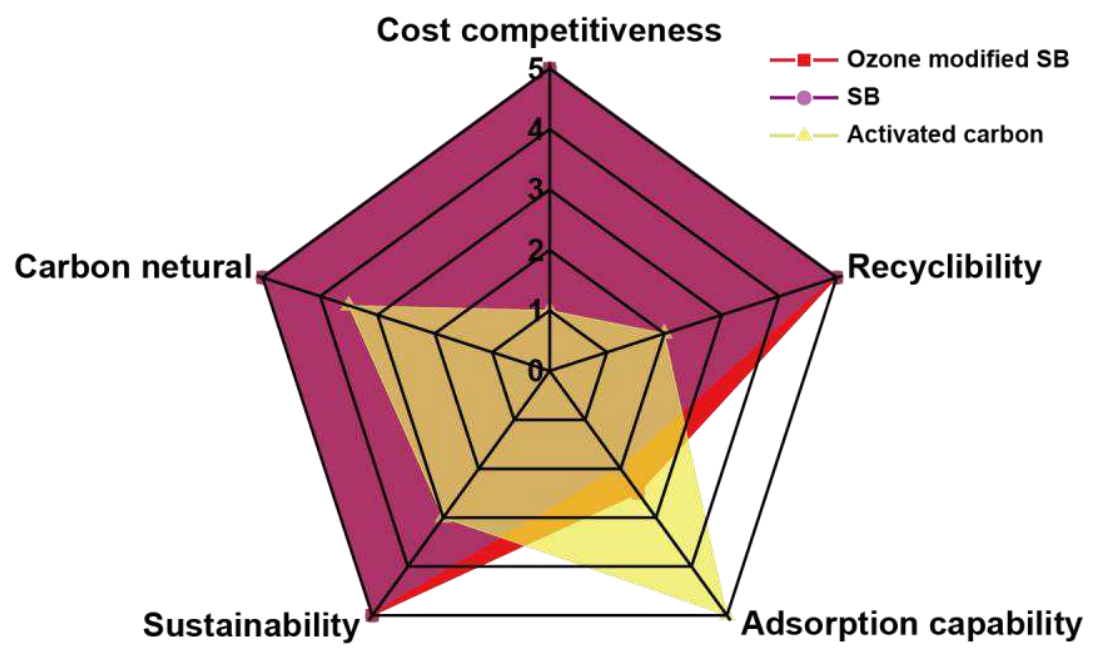

476 Figure 6 Radar chart showing cost efficiency, recyclability, carbon neutral, sustainability, and 477 good adsorption capability of ozone modified SB, compared to original SB and activated 478 carbon.

\section{Conclusion}

In this study, SB was successfully modified by ozone at normal pressure and temperature. High yield (95.9\%), low lignin content (21.9\% total lignin removals), and high content of functional groups containing SB was obtained with only $1.5 \mathrm{wt} \%$ ozone consumption. The total content of carboxyl groups as the main adsorption sites for cationic organic pollutants was increased by about $84.1 \%$. The increase of the functional groups and reduction of the lignin coverage by ozone modification increased the adsorption abilities of SB. The maximum adsorption rate and capacity of SB for MB were increased by about $33.3 \%$ and $11.3 \%$, compared to the original SB. Besides, ozone modified SB maintained its high adsorption capability even at high $\mathrm{NaCl}$ concentration $(0.6 \mathrm{M})$. For cationic polymer with high charges (PDADMAC), the adsorption capacity of the milled SB increased about $125.4 \%$. A further increase in the ozone consumption, however, would not increase the adsorption abilities but 
could decrease the yield. Considering ozone as an efficient and green reactant, ozone

492

494

496

modification is believed to be a promising method for increasing the adsorption abilities of lignocellulosic materials towards cationic organic pollutants.

\section{Acknowledgments}

This research was supported by the Guangzhou Science and Technology Plan Projects (NO. 201707020011), the National Science and Technology Major Project (NO. 2017ZX07402004), the State Key Laboratory of Pulp and Paper Engineering (NO. 201831), and Guangdong Province Science Foundation for Cultivating National Engineering Research Center for Efficient Utilization of Plant Fibers (NO. 2017B090903003).

\section{Reference}

(1) Guillen, J.; Natale, F.; Carvalho, N.; Casey, J.; Hofherr, J.; Druon, J.-N.; Fiore, G.; Gibin, M.; Zanzi, A.; Martinsohn, J. T. Global seafood consumption footprint. Ambio 2019, 48 (2), 111-122.

(2) Livingstone, D.; Gallacher, S. Contamination and Spoilage of Molluscs and Crustaceans. In Encyclopaedia of Food Sciences and Nutrition; Academic Press: Boston, 2003; pp 5228-5245.

(3) Zhou, Y.; Lu, J.; Zhou, Y.; Liu, Y. Recent advances for dyes removal using novel adsorbents: a review. Environ. Pollut. 2019, 252, 352-365.

(4) Gupta, V. K.; Ali, I.; Saleh, T. A.; Nayak, A.; Agarwal, S. Chemical treatment technologies for waste-water recycling - an overview. RSC Adv. 2012, 2 (16), 6380-6388.

(5) Aksu, Z. Application of biosorption for the removal of organic pollutants: a review. Process Biochem. 2005, 40 (3-4), 997-1026.

(6) Yan, J.; Oyedeji, O.; Leal, J. H.; Donohoe, B. S.; Semelsberger, T. A.; Li, C.; Hoover, A. N.; Webb, E.; Bose, E. A.; Zeng, Y. Engineering, Characterizing Variability in Lignocellulosic Biomass: A Review. ACS Sustainable Chem. Eng. 2020, 8 (22), 8059-8085.

(7) Schreiber, M.; Vivekanandhan, S.; Mohanty, A. K.; Misra, M. A study on the electrospinning behaviour and nanofibre morphology of anionically charged lignin. Adv Mat Lett. 2012, 3, 476.

(8) O’ Connell, D. W.; Birkinshaw, C.; O’ Dwyer, T. F. Heavy metal adsorbents prepared from the modification of cellulose: A review. Bioresour. Technol. 2008, 99 (15), 6709-6724.

(9) Alen, R.; Andersson, R.; Annergreen, G.; Berg, C.-G.; Chirat, C.; van Dam, J.; Danielsson, M.; Engelfeldt, A.; Engstrom, J.; Germgard, U., Chemical pulping Part 1, fibre chemistry and Technology; Paper Engineers' Association/Paperi ja Puu Oy: Helsinki, 2011; Vol. 6. 
(10) Mooney, C. A.; Mansfield, S. D.; Touhy, M. G.; Saddler, J. N. The effect of initial pore volume and lignin content on the enzymatic hydrolysis of softwoods. Bioresour. Technol. 1998, 64 (2), 113-119.

(11) Ben, H.; Chen, X.; Han, G.; Shao, Y.; Jiang, W.; Pu, Y.; Ragauskas, A. J. Characterization of whole biomasses in pyridine based ionic liquid at low temperature by 31P NMR: an approach to quantitatively measure hydroxyl groups in biomass as their original structures. Front. Energy Res. 2018, 6, 13.

(12) Balousek, P. J. The effects of ozone upon a lignin-related model compound containing a beta-aryl ether linkage; Lawrence University: Appleton, 1979, pp. 3 - 4 (1979).

(13) Pouyet, F.; Chirat, C.; Potthast, A.; Lachenal, D. Formation of carbonyl groups on cellulose during ozone treatment of pulp: Consequences for pulp bleaching. Carbohydr. Polym. 2014, 109, 85-91.

(14) Lemeune, S.; Jameel, H.; Chang, H. M.; Kadla, J., Effects of ozone and chlorine dioxide on the chemical properties of cellulose fibers. J APPL POLYM SCI 2004, 93 (3), 1219-1223.

(15) Abdolali, A.; Guo, W.; Ngo, H. H.; Chen, S.-S.; Nguyen, N. C.; Tung, K. L. Typical lignocellulosic wastes and by-products for biosorption process in water and wastewater treatment: a critical review. Bioresour. Technol. 2014, 160, 57-66.

(16) Gellerstedt, F.; Gatenholm, P. Surface properties of lignocellulosic fibers bearing carboxylic groups. Cellulose 1999, 6 (2), 103-121.

(17) Zhang 1, Y.; Sjögren, B.; Engstrand 2, P.; Htun, M. Determination of charged groups in mechanical pulp fibres and their influence on pulp properties. J. Wood Chem. Technol. 1994, 14 (1), 83-102.

(18) Belgacem, M.; Czeremuszkin, G.; Sapieha, S.; Gandini, A. Surface by XPS characterization and inverse gas of cellulose fibres chromatography. Cellulose 1995, 2 (3), 145-157.

(19) Saha, P.; Chowdhury, S.; Gupta, S.; Kumar, I. Insight into adsorption equilibrium, kinetics and thermodynamics of Malachite Green onto clayey soil of Indian origin. Chem. Eng. J. 2010, 165 (3), 874-882.

(20) Wang, H.; Yuan, X.; Zeng, G.; Leng, L.; Peng, X.; Liao, K.; Peng, L.; Xiao, Z.,Removal of malachite green dye from wastewater by different organic acid-modified natural adsorbent: kinetics, equilibriums, mechanisms, practical application, and disposal of dye-loaded adsorbent. Environ. Sci. Pollut. Res. 2014, 21 (19), 11552-11564. (21) Salima, A.; Benaouda, B.; Noureddine, B.; Duclaux, L. Application of Ulva lactuca and Systoceira stricta algae-based activated carbons to hazardous cationic dyes removal from industrial effluents. Water Res. 2013, 47 (10), 3375-3388.

(22) Ncibi, M. C.; Mahjoub, B.; Seffen, M.; Kinetic and equilibrium studies of methylene blue biosorption by Posidonia oceanica (L.) fibres. J Hazard Mater. 2007, 139(2), 280-285.

(23) Kumar, K.V.; Sivanesan, S.; Ramamurthi, V.;. Adsorption of malachite green onto Pithophora sp., a fresh water algae: equilibrium and kinetic modelling. Process Biochem. 2005, 40(8), 2865-2872.

(24) Ho, Y. S.; McKay, G. Pseudo-second order model for sorption processes. Process Biochem. 1999, 34 (5), 451-465.

(25) Ho, Y. S. Second-Order Kinetic Model for the Sorption of Cadmium onto Tree Fern: A Comparison of Linear and Non-Linear Methods. Water Res. 2006, 40 (1), 119-125.

(26) Chowdhury, S.; Saha, P. Pseudo-Second-Order Kinetic Model for Biosorption of Methylene Blue onto Tamarind Fruit Shell: Comparison of Linear and Nonlinear Methods. Bioremediat. J. 2010, 14 (4), 196-207.

(27) Vadivelan, V.; Kumar, K. V. Equilibrium, kinetics, mechanism, and process design for the sorption of methylene blue onto rice husk. J. Colloid Interface Sci. 2005, 286 (1), 90-100.

(28) Aksu, Z.; Tezer, S. Equilibrium and kinetic modelling of biosorption of Remazol Black B by Rhizopus arrhizus in a batch system: effect of temperature. Process Biochem. 2000, 36 (5), 431-439.

(29) Namasivayam, C.; Kavitha, D. Removal of Congo Red from water by adsorption onto activated carbon prepared from coir pith, an agricultural solid waste. Dyes Pigm. 2002, 54 (1), 47-58. 
(30) Dai, C.; Yang, L.; Xie, J.; Wang, T.-J. Physicochemical, S. A.; Aspects, E., Nutrient diffusion control of fertilizer granules coated with a gradient hydrophobic film. Colloids Surf., A 2020, 588, 124361.

(31) Öner, M.; Doğan, Ö.; Öner, G. The influence of polyelectrolytes architecture on calcium sulfate dihydrate growth retardation. J. Cryst. Growth 1998, 186 (3), 427-437.

570 (32) Wågberg, L. Polyelectrolyte adsorption onto cellulose fibres - A review. NORD PULP PAP RES J 2000, 15 571 (5), 586-597.35.

572 (33) Lloyd J A, Horne C W. The determination of fibre charge and acidic groups of radiata pine pulps. NORD 573 PULP PAP RES J. 1993, 08 (1), 048-052.

574 (34) Röhrling, J.; Potthast, A.; Rosenau, T.; Lange, T.; Borgards, A.; Sixta, H.; Kosma, P. A novel method for the 575 determination of carbonyl groups in cellulosics by fluorescence labeling. 2. Validation and applications. 576 Biomacromolecules 2002, 3 (5), 969-975.

577 (35) Liao, J.; He, S.; Mo, L.; Guo, S.; Luan, P.; Zhang, X.; Li, J. Mass-Production of High-Yield and HighStrength Thermomechanical Pulp Fibers from Plant Residues Enabled by Ozone Pretreatment. J. Cleaner Prod. $579 \mathbf{2 0 2 1}, 126575$.

580 (36) Freudenberg, K.; Neish, A. C. Constitution and biosynthesis of lignin. In Constitution and biosynthesis of 581 lignin; Springer: New York, 1968.

582 (37) Kocaefe, D.; Huang, X.; Kocaefe, Y.; Boluk, Y. Quantitative characterization of chemical degradation of 583 heat - treated wood surfaces during artificial weathering using XPS. Surf. Interface Anal. 2013, 45 (2), 639-649.

584 (38) Ren, J.-L.; Sun, R.-C.; Peng, F. Carboxymethylation of hemicelluloses isolated from sugarcane bagasse. 585 Polym. Degrad. Stab. 2008, 93 (4), 786-793.

586 (39) Laine, J.; Stenius, P.; Carlsson, G.; Ström, G. Surface characterization of unbleached kraft pulps by means 587 of ESCA. Cellulose 1994, 1 (2), 145-160. 
590 All figures and TOC graphic in this article is free domain

$591 \quad$ TOC graphic

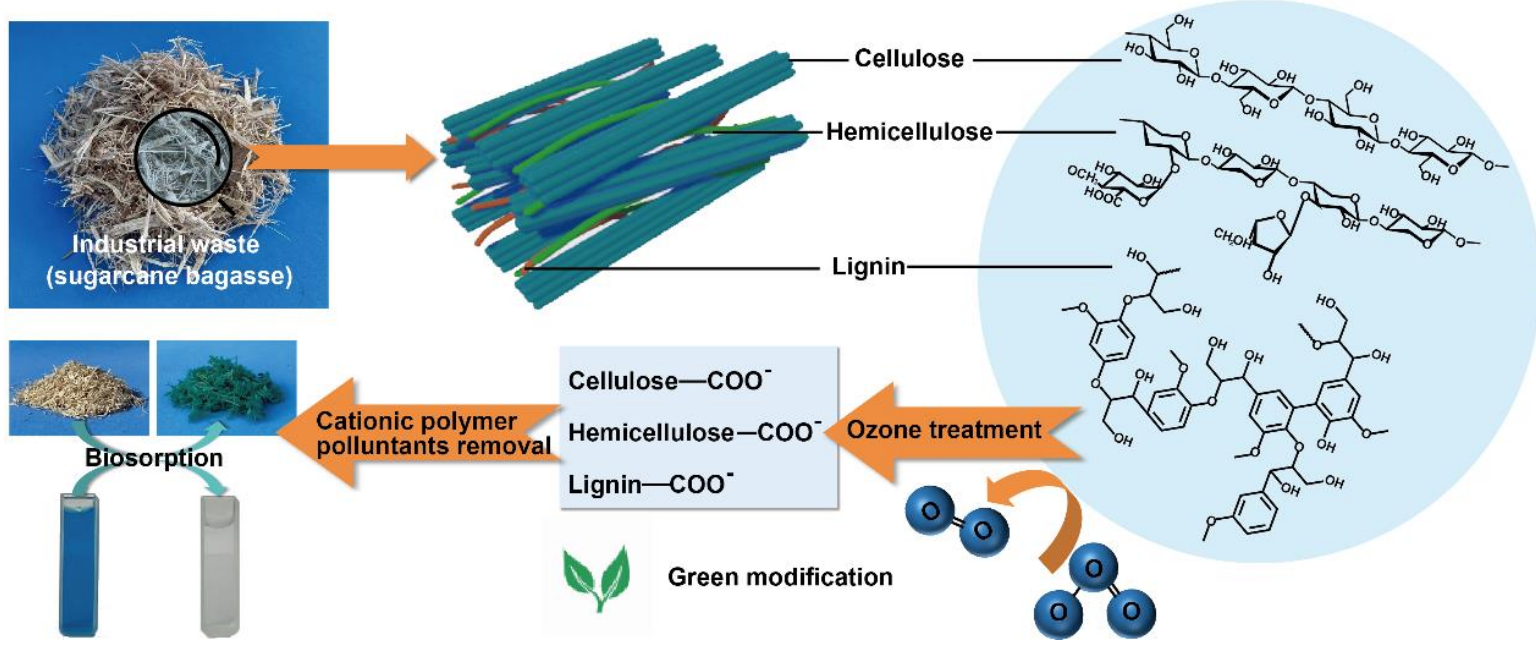

592 